\title{
Intra-muscular transplantation improves engraftment rates for esophageal patient-derived tumor xenografts
}

Matthew Read, MBBS ${ }^{1,2}$, David Liu, MBBS, BMedSci ${ }^{1,2}$, Cuong P. Duong, MBBS, FRACS, $\mathrm{PhD}^{1,3}$, Carleen Cullinane $\mathrm{PhD}^{1,2}$, William K Murray, MBBS, FRCPA, FRCPath $^{5}$, Christina Fennell BBiomedSc(hons) ${ }^{1,2}$, Jake Shortt, BMedSc, MBChB, FRACP, FRCPA, $\mathrm{PhD}^{2,6,7}$, David Westerman, MBBS, FRACP, FRCPA, FFSc ${ }^{5,8}$, Paul Burton, MBBS, FRACS, PhD 9,10 , Nicholas J. Clemons, BSc(hons), $\mathrm{PhD}^{1,2,4 *}$ and Wayne A. Phillips, BSc(hons), $\mathrm{PhD}^{1,2,3,4} * \quad$ (*co-senior authors)

${ }^{1}$ Surgical Oncology Research Laboratory, Peter MacCallum Cancer Centre, Melbourne, Victoria, Australia; ${ }^{2}$ Sir Peter MacCallum Department of Oncology, University of Melbourne, Melbourne, Victoria, Australia; ${ }^{3}$ Division of Cancer Surgery, Peter MacCallum Cancer Centre, Melbourne, Victoria, Australia; ${ }^{4}$ University of Melbourne Department of Surgery, St. Vincent’s Hospital, Melbourne, Victoria; ${ }^{5}$ Department of Pathology, Peter MacCallum Cancer Centre, Melbourne, Australia; ${ }^{6}$ School of Clinical Sciences at Monash Health, Australia; ${ }^{7}$ Faculty of Medicine, Nursing \& Health Sciences; Monash University, Australia; ${ }^{8}$ University of Melbourne, Melbourne, Australia; ${ }^{9}$ Monash University Centre for Obesity Research and Education, Alfred Hospital, Melbourne; ${ }^{10}$ Cabrini Hospital, Melbourne, Victoria.

Running head: Improved engraftment of esophageal PDTXs

Synopsis: This study reports the development and validation of a novel intramuscular transplantation technique that improves the engraftment rate of esophageal cancer patient-derived tumor xenografts. 
Key Words: Patient derived xenograft (PDX), intramuscular (IM), cryopreservation, esophageal adenocarcinoma (EAC), esophageal squamous cell carcinoma (ESCC), preclinical model.

Disclosures: No disclosures

Corresponding Author: Wayne A. Phillips PhD

Surgical Oncology Research Laboratory

Peter MacCallum Cancer Centre

Locked Bag 1 A’Beckett Street

Melbourne, VIC, 8006. Australia.

Email: wayne.phillips@petermac.org 


\begin{abstract}
Background: Recently, there has been an increase in the availability of targeted molecular therapies for cancer treatment. However, the application of these approaches to esophageal cancer has been hampered by the relative lack of appropriate models for preclinical testing. Patient-derived tumor xenograft (PDTX) models are gaining popularity in many cancers. Unfortunately, these models have proven difficult to generate in esophageal cancer.
\end{abstract}

Aim: The purpose of this study was to improve the engraftment efficiency of esophageal PDTX.

Methods: Fresh pieces of esophageal tumors, obtained from either endoscopic biopsy or resected specimen, were transplanted into immunocompromised mice, either subcutaneously or intramuscularly and monitored for tumor formation.

Results: Using our novel intramuscular technique, successful engraftment was achieved from all 18 patients attempted. Thirteen of these PDTXs recapitulated the original patient tumors with respect to degree of differentiation, molecular and genetic profile, and chemotherapeutic response. However, lymphomatous transformation was observed in the remaining five PDTX. Successful engraftment was only achieved from one of six patients using the classical subcutaneous approach.

Discussion: Using our novel intramuscular transplant technique, we have achieved a much higher engraftment rate of PDTX when compared with other published studies. It is hoped that this advancement will help to expedite the development and testing of new therapies for esophageal cancer. 


\section{Background}

Esophageal cancer is currently the eighth most common cancer worldwide and has an extremely high case fatality rate ${ }^{1}$. Eighty three percent of all cases occur in developing countries, where squamous cell carcinoma is the main subtype ${ }^{2}$. However, in the developed world, esophageal adenocarcinoma poses the greater problem, as its incidence has risen more than six-fold over the last four decades ${ }^{3}$. Currently, in the United States, only $17.5 \%$ of all patients who present with esophageal cancer will survive greater than five-years ${ }^{4}$. Alternative treatment strategies are needed to improve disease outcomes. Unfortunately, progress is being hampered by a lack of suitable pre-clinical models with which to study the disease and test new therapies.

One model that has shown great promise in the field of cancer research is patientderived tumor xenografts (PDTX), in which patient tumor tissue is grown and expanded in immunocompromised mice. As these models recapitulate the original patient tumors with respect to histology, molecular and genetic profile and therapeutic response, they are being increasingly used as preclinical models for drug target validation and biomarker discovery ${ }^{5}$. PDTX also have the capacity to provide a perpetual tissue bank making them a valuable resource, particularly in esophageal cancer where the collection of treatment naïve tissue is often limited to small endoscopic biopsies obtained prior to neoadjuvant therapy ${ }^{6}$. Unfortunately, there has only been limited success in generating esophageal PDTX with success rates ranging between 30 to $38.5 \%^{7-13}$. 
Given the importance of the PDTX model to cancer research, refinements that lead to improvements in engraftment efficiencies are of great benefit ${ }^{14}$. One variable with the potential to improve engraftment efficiency is the transplantation site. Common sites for heterotopic transplantation include both subcutaneous (SC) and renal subcapsular spaces $^{5}$. However, we hypothesized that an intramuscular (IM) transplantation site would be associated with an improved engraftment of PDTX due to the wellvascularized transplant bed it provides. 


\section{Materials and Methods}

Mice

Scid, NOD scid, NOD-scid IL2 receptor gamma chain knockout (NSG), and athymic nude mice were obtained from either the Animal Resource Centre (Canning Vale, Western Australia), the Walter \& Eliza Hall Institute (Melbourne, Victoria) or bred internally at the Peter MacCallum Cancer Centre (Melbourne, Victoria). All mice were maintained and housed in the animal facility of the Peter MacCallum Cancer Centre. All experimental procedures involving animals were approved by the Peter MacCallum Cancer Centre Animal Experimental Ethics Committee and conducted in accordance with the National Health and Medical Research Council (NHMRC) Australian code for the care and use of animals for scientific purposes (8th edition, 2013).

\section{Tissue Collection \& Preparation}

Patient tissue was collected from the Peter MacCallum Cancer Centre, the Cabrini Medical Centre, and other hospitals through the Victorian Cancer Biobank between March 2012 and June 2014. The collection and use of human tissue for this project was approved by the Ethics Committee of the Peter MacCallum Cancer Centre and carried out according to the NHMRC National statement on ethical conduct in human research (2007).

After obtaining informed consent, fresh samples of esophageal tumors were collected either by endoscopic biopsy or from surgical resection specimens and placed in chilled phosphate-buffered saline (PBS) supplemented with $200 \mathrm{U} / \mathrm{ml}$ penicillin and $200 \mu \mathrm{g} / \mathrm{ml}$ streptomycin $\left(\mathrm{PBS}^{++}\right.$) and kept on ice. Samples were divided into 
approximately $2 \mathrm{~mm}^{3}$ sized pieces with any necrotic areas being discarded. Representative fragments were also snap frozen for DNA/RNA analysis or fixed in $10 \%$ buffered formalin for histology. The remaining tumor pieces were placed in Matrigel $^{\mathrm{TM}}$ (BD Biosciences, NJ, USA) and kept on ice until implantation. All tissue was implanted within 90 minutes of collection.

\section{Implantation \& Monitoring}

Mice were anesthetized via an intraperitoneal injection of $100 \mu \mathrm{l}$ of anesthetic solution (10 mg/ml ketamine and $2 \mathrm{mg} / \mathrm{ml}$ xylazine) per $10 \mathrm{~g}$ of body weight and the dorsum of the mouse shaved and prepared with a $2 \%(\mathrm{v} / \mathrm{v})$ chlorhexidine gluconate / 70\% (v/v) isopropyl alcohol solution. Under aseptic conditions, a $15 \mathrm{~mm}$ midline incision was made, immediately caudal to the dorsal hump. Using blunt dissection, a skin flap was raised and the skin retracted laterally. For IM implantation, a superficial stay suture was placed within the dorsal musculature immediately caudal to the lowest rib using a $4 / 0$ braided absorbable suture. After tenting the muscle fibers, an IM pocket was created using a combination of both sharp and blunt dissection until just large enough to accommodate a piece of tumor. A tumor piece coated in Matrigel ${ }^{\mathrm{TM}}$ was then placed in the IM pocket prior to it being sutured closed (Supplementary Fig. 1). For SC implantation, the tumor piece was implanted under the raised skin flap. Up to two separate transplantation sites were used per mouse. The skin was closed using a 3/0 braided absorbable suture. Mice were closely monitored for tumor formation and humanely euthanized once tumors reached the ethical limit of $1,500 \mathrm{~mm}^{3}$, as calculated by the formula (length $\times$ width $^{2}$ )/2, or at any sign of discomfort and/or stress. 
Harvesting \& Processing of PDTX

PDTX were carefully resected to ensure that the muscle layer was dissected free. After debridement of any necrotic areas, the PDTX was divided into $2 \mathrm{~mm}^{3}$ sized pieces and processed as per the original tissue. For cryopreservation, pieces were washed with $\mathrm{PBS}^{++}$then aliquoted into cryovials (up to 2 per cryovial) containing 1 $\mathrm{ml}$ of fetal calf serum containing 10\% (v/v) dimethylsulfoxide (DMSO) and frozen to $-80^{\circ} \mathrm{C}$ at approximately $-1^{\circ} \mathrm{C} / \mathrm{min}$.

\section{Histology \& Immunohistochemistry}

Sections of formalin-fixed paraffin-embedded (FFPE) tissue from all original patient derived tissues and PDTX were stained with haematoxylin and eosin (H\&E). Immunohistochemistry was performed using antibodies against the following proteins: human mitochondrial antigen (MAB1273, Merck Millipore, Billerica, MA, 1:500), CK7 (OV-TL 12/30, DakoCytomation, Glostrup, Denmark, 1:50), CK19 (RCK108, DakoCytomation, 1:100).

\section{DNA Extraction \& Sequencing}

DNA was extracted from freshly frozen pieces of tissue using the DNeasy Blood and Tissue kit (QIAGEN) as per the recommended protocol. Targeted sequencing across a panel of 48 known oncogenes was then performed using the Illumina TruSeq Amplicon Cancer Panel as previously described ${ }^{15}$. 


\section{Therapeutic Response}

For assessment of chemotherapeutic response, PDTX were serially passaged into cohorts of up to 18 mice, using the IM technique. Athymic nude mice were selected for this purpose due to the ease of tumor detection and better tolerance of the chemotherapy. Once tumors reached a volume of $125 \mathrm{~mm}^{3}$, mice were randomized to receive either the matched patient chemotherapy (5-fluorouracil (5-FU) / cisplatin), or vehicle treatment. Cisplatin $\left(\mathrm{DBL}^{\mathrm{TM}}\right)$ was suspended in $0.9 \%(\mathrm{w} / \mathrm{v}) \mathrm{NaCl}$ and administered at a dose of $4 \mathrm{mg} / \mathrm{kg}$ via intraperitoneal injection on a weekly basis for three weeks. 5-FU ( $\left.\mathrm{DBL}^{\mathrm{TM}}\right)$ was suspended in $0.9 \% \mathrm{NaCl}$ and administered at 10 $\mathrm{mg} / \mathrm{kg}$ via intraperitoneal injection on a daily basis for five days followed by nine rest days. This cycle was repeated twice. Vehicle consisted of $0.9 \% \mathrm{NaCl}$. 


\section{Results}

Tumor samples from 23 patients were harvested from the esophagus, gastroesophageal junction (GEJ) or peritoneum (metastatic deposit from a primary GEJ tumor) and included both adenocarcinoma and SCC. Between one and four tumor pieces (mode=2) from each patient were implanted. Samples from four patients were lost owing to the premature death of the host mice within the first month (i.e. before a tumor could establish) and were excluded from further analysis. Of the remaining patients, samples implanted using the IM technique had a per implant success rate of 24 from 37 (65\%) and resulted in the successful engraftment of at least one implant from all 18 patients attempted with this method (Table 1). In comparison, the SC technique had a per implant success rate of only 1 of 11 (9\%) and was associated with the successful engraftment of just 1 of 6 (16\%) patients attempted with this method (Table 1).

All engrafted tissues were subjected to thorough histopathological analysis by an experienced histopathologist. All were demonstrated to be composed of human tissue, as demonstrated by staining with anti-human mitochondrial antibody (Fig. 1a). Of the 18 engrafted lines, 13 were confirmed to be of epithelial origin and to have maintained the same degree of differentiation (Fig. 1a) and expression of molecular markers (Fig. 1b) as their parent tumor. Thus we were able to successfully establish bona fide esophageal PDTX from 13 of 18 patients (72\%) using the IM technique compared to just 1 from 6 patients by the SC method. Of the 13 esophageal PDTX lines successfully established, nine were obtained by endoscopic biopsy and four were 
from surgical resection. Two of the 13 esophageal PDTX were derived from patients who had been treated with neoadjuvant therapy.

Of the five IM xenografts that failed to recapitulate their parent tumors, four were confirmed to be B cell lymphomas and one was composed of a combination of both epithelial and lymphoid cells (Supplementary Fig. 2a\&b). These lymphomas stained strongly for Epstein-Barr Virus (EBV) RNA (Supplementary Fig. 2d), indicating that latent EBV may be the driver of this lymphomatous transformation. These five lymphoma lines were also reproducibly metastatic in the mouse, with extranodal dissemination frequently noted in the lung, liver and spleen (data not shown).

All the validated esophageal PDTX lines have now been passaged multiple times (up to seven) and continue to maintain their molecular and histological phenotypes. We have also been able to successfully re-establish four out of five esophageal PDTX lines following cryopreservation. All passages were performed in NSG mice except for the failed cryopreserved sample, which was implanted into NOD SCID mice (Table 1). 
Targeted sequencing of 48 known cancer related genes revealed the model to be relatively genetically stable. From a single PDTX line (Patient 1), the original tumor was compared to seven PDTX across three consecutive generations. Our results identified the presence of synonymous variants in five genes (FGFR3, PDGFRA, EGFR, RET, PTEN) and non-synonymous variants in three genes (HNF1A, TP53, STK11) in the parent tumor and all were maintained in the original PDTX and subsequent passages, with the exception of one-second generation PDTX in which the STK11 variant was not detected.

Importantly, we have also confirmed that the therapeutic responses observed in the patients are reproduced within the PDTX. For example, patient 11, who had a poorly differentiated SCC of the mid to lower esophagus, experienced a complete response to the combination of chemotherapy (5-FU and cisplatin) and radiotherapy (50.4 Gy over 28 fractions). This complete response was mirrored in the matching PDTX (Fig 2a). Similarly, patient 15 , who was receiving treatment for a moderately differentiated adenocarcinoma of the GEJ, demonstrated only a partial response to the combination of chemotherapy (5-FU and cisplatin) and radiotherapy (50.4 Gy over 28 fractions) and this partial response was mirrored in the matching PDTX (Fig. 2b). 


\section{Discussion}

We report here a methodology for the improved establishment of PDTX from esophageal tumors. Using this novel IM technique we have been able to establish esophageal PDTX lines from 13 of 18 patients. These results suggest that this IM transplantation technique is more robust than the standard SC approach for the generation of esophageal PDTX. Given both our early success using the IM technique and the importance placed on generating additional PDTX lines from the limited quantity of tissue available, the majority of specimens within our series were implanted using the IM technique. For this reason, the numbers were too low for a direct comparison of the take rate between the IM and SC techniques. Nevertheless, when compared to the published engraftment rates across a range of reported esophageal PDTX series ${ }^{7-13}$, the IM technique appears to be superior. However, caution is needed when making such a comparison, as the small numbers mean it is not possible to standardize for variables such as ischemic time and tumor viability.

We postulate that the improved take rate observed with the IM technique can be attributed to the greater blood supply within the transplant bed. Evidence for this can be extrapolated from a study into the ectopic transplantation of ovarian tissue ${ }^{16}$. In this study, a comparison of the SC and IM transplantation sites was performed through a series of experiments involving the xenografting of normal rat ovarian tissue into nude mice. Results demonstrated that the SC transplantation site was associated with pericyte loss and tissue damage, whereas the IM site was associated with vascular maintenance and tissue preservation ${ }^{16}$. It is also well established that muscle tissue has greater autoregulatory control over blood flow compared to 
cutaneous tissues ${ }^{17}$. This ensures that the temperature within the transplant bed remains relatively constant, protecting the tumor graft against hypothermic insult.

We have confirmed that the esophageal PDTX within our series are composed of human tissue and that they are representative of the original patient tumor with respect to degree of differentiation and both molecular and genetic phenotype. By assessing the response to standard chemotherapy, we have also produced evidence that the biology of the PDTX matches that of the original tumor. This highlights the potential power of well-validated PDTX as pre-clinical tools.

The feasibility of cryopreserving esophageal PDTX has also been demonstrated in this study. This has the potential to lead to significant reductions in the resources required to maintain perpetual PDTX bio-banks. It also gives researchers the ability to more readily share PDTX resources with collaborators.

Researchers also need to be cognizant of potential limitations when using PDTX models. Five of the initial 18 established xenografts (26\%) underwent lymphomatous transformation. As it is not easy to distinguish poorly differentiated carcinomas from lymphomas by histology alone, it is important that poorly differentiated PDTX are tested for expression of lymphoma markers. Indeed, the process of lymphomatous transformation within xenografts has only recently been reported ${ }^{7,18,19}$, but can be as high as $68 \%$ as reported in one series ${ }^{19}$. It is most likely that the lymphomas arise through transformation of EBV infected B-cells that have been transplanted with the tissue piece into a permissive environment and is akin to the development of lymphomas in immunodeficient patients, putatively modeling an EBV-driven post- 
transplant lymphoproliferative disorder ${ }^{20}$. Given the high rate of EBV infection within the general population it seems likely that this phenomenon has either been under-recognized or under-reported in the literature.

In summary, we have demonstrated that an IM transplant technique is associated with the improved engraftment of esophageal PDTX. Given the importance of the PDTX as a pre-clinical tool, it is hoped that such a refinement will lead to a greater understanding of cancer biology and improved therapeutics.

\section{ACKNOWLEDMENTS}

This work was supported by a National Health and Medical Research Council (NHMRC) of Australia Centres for Research Excellence grant (1040947). MR was supported by the Thornell-Shore Memorial scholarship from the Royal Australasian College of Surgeons (RACS) and the Sir Thomas Naghten Fitzgerald scholarship from The University of Melbourne. DL was supported by both the John Loewenthal and Reg Worcester Research Fellowships through the RACS Foundation for Surgery in addition to an Australian Postgraduate Research award from the NHMRC. JS is supported by the Victorian Cancer Agency / Snowdome Foundation 'Eva \& Les Erdi Fellowship'. Some tissue samples used in this project were provided by the Victorian Cancer Biobank with appropriate ethics approval. The Victorian Cancer Biobank is supported by the Victorian Government, Australia. 


\section{REFERENCES}

1. Ferlay J, Shin HR, Bray F, Forman D, Mathers C, Parkin DM. Estimates of worldwide burden of cancer in 2008: GLOBOCAN 2008. Int J Cancer 2010; 127:2893-917.

2. Jemal A, Bray F, Center MM, Ferlay J, Ward E, Forman D. Global cancer statistics. CA Cancer J Clin 2011; 61:69-90.

3. Pohl H, Welch HG. The role of overdiagnosis and reclassification in the marked increase of esophageal adenocarcinoma incidence. J Natl Cancer Inst 2005; 97:142-6.

4. SEER Cancer Statistics Factsheets: Esophageal Cancer. National Cancer Institute. Bethesda, MD Available:

http://seer.cancer.gov/statfacts/html/esoph.html [accessed November 5, 2014].

5. Tentler JJ, Tan AC, Weekes CD, Jimeno A, Leong S, Pitts TM, Arcaroli JJ, et. al. Patient-derived tumour xenografts as models for oncology drug development. Nat Rev Clin Oncol 2012; 9:338-50.

6. Boonstra JJ, Tilanus HW, Dinjens WNM. Translational research on esophageal adenocarcinoma: from cell line to clinic. Dis Esophagus DOI: 10.1111/dote.12095 [Online June 24, 2013].

7. Dodbiba L, Teichman J, Fleet A, Thai H, Sun B, Panchal D, Patel D, et. al. Primary esophageal and gastro-esophageal junction cancer xenograft models: clinicopathological features and engraftment. Lab Invest 2013; 93:397-407.

8. Rumpel CA, Powell SM, Moskaluk CA. Mapping of Genetic Deletions on the Long Arm of Chromosome 4 in Human Esophageal Adenocarcinomas. Am J Pathol 1999; 154:1329-1334. 
9. Boonstra JJ, van Marion R, Douben HJ, Lanchbury JS, Timms KM, Abkevich V, Tilanus HW, et. al. Mapping of homozygous deletions in verified esophageal adenocarcinoma cell lines and xenografts. Genes Chromosomes Cancer 2012; 51:272-82.

10. de Both NJ, Wijnhoven BPL, Sleddens HFBM, Tilanus HW, Dinjens WNM. Establishment of cell lines from adenocarcinomas of the esophagus and gastric cardia growing in vivo and in vitro. Virchows Archiv 2001; 438:451-456. 451456.

11. El-Rifai W, Harper JC, Cummings OW, Hyytinen ER, Frierson HF Jr, Knuutila S, Powell SM. Consistent genetic alterations in xenografts of proximal stomach and gastro-esophageal junction adenocarcinomas. Cancer Res 1998; 58:34-37.

12. Zhang J, Jiang D, Li X, Lv J, Xie L, Zheng L, Gavine PR, et. al. Establishment and characterization of esophageal squamous cell carcinoma patient-derived xenograft mouse models for preclinical drug discovery. Lab Invest 2014; 94:917-26.

13. Wang Z, Da Silva TG, Jin K, Han X, Ranganathan P, Zhu X, Sanchez-Mejias A, et. al. Notch signaling drives stemness and tumorigenicity of esophageal adenocarcinoma. Cancer Res 2014; 74:6364-74.

14. Hidalgo M, Amant F, Biankin AV, Budinska E, Byrne AT, Caldas C, Clarke RB, et. al. Patient-derived xenograft models: an emerging platform for translational cancer research. Cancer Discov 2014; 4:998-1013.

15. Clemons NJ, Do H, Fennell C, Deb S, Fellowes A, Dobrovic A, Phillips WA. Characterization of a novel tumorigenic esophageal adenocarcinoma cell line: OANC1. Dig Dis Sci 2014; 59:78-88. 
16. Israely $\mathrm{T}$, Dafni $\mathrm{H}$, Granot $\mathrm{D}$, Nevo $\mathrm{N}$, Tsafriri $\mathrm{A}$, Neeman $\mathrm{M}$. Vascular remodeling and angiogenesis in ectopic ovarian transplants: a crucial role of pericytes and vascular smooth muscle cells in maintenance of ovarian grafts. Biol Reprod 2003; 68:2055-64.

17. Braunwald E. Regulation of the Circulation. N Engl J Med 1974; 290:142025.

18. John T, Yanagawa N, Kohler D, Craddock KJ, Bandarchi-Chamkhaleh B, Pintilie M, Sykes J, et. al. Characterization of lymphomas developing in immunodeficient mice implanted with primary human non-small cell lung cancer. J Thorac Oncol 2012; 7:1101-8.

19. Chen K, Ahmed S, Adeyi O, Dick JE, Ghanekar A. Human solid tumor xenografts in immunodeficient mice are vulnerable to lymphomagenesis associated with Epstein-Barr virus. PLoS One 2012; 7:e39294.

20. Vockerodt M, Yap LF, Shannon-Lowe C, Curley H, Wei W, Vrzalikova K, Murray PG. The Epstein-Barr Virus and the Pathogenesis of Lymphoma. J Pathol DOI: 10.1002/path.4459 [Online October 8, 2014].

21. Craig FE, Foon KA. Flow cytometric immunophenotyping for hematologic neoplasms. Blood 2008; 111:3941-67. 


\section{Figure Legends}

Figure 1: PDTX recapitulate the original patient tumor. (a) H\&E staining (original tumor and PDTX) and immunohistochemistry using an anti-human mitochondrial antibody (PDTX only) in a poorly differentiated esophageal adenocarcinoma (Patient 1, top panels) and an esophageal SCC (Patient 11, bottom panels). (b) H\&E staining and immunohistochemistry using CK7 and CK19 antibodies in a gastro-esophageal junctional (GEJ) adenocarcinoma (Patient 15, top panels) and the corresponding PDTX (bottom panels).

Figure 2: Assessment of tumor biology. Pre- and post-treatment ${ }^{18}$ F-FDG-PET images and the growth curves for the respective PDTX with and without treatment with matched chemotherapy (cisplatin/5-FU) from representative patients who had either a complete metabolic response (a, Patient 11) or partial metabolic response (b, Patient 15) to their neoadjuvant treatment (cisplatin/5-FU). Shown are mean \pm SEM. An unpaired t-test was performed on all data points using GraphPad Prism 5.0. ${ }^{*} \mathrm{p}<0.05$ for drug treated compared to vehicle control at same time point. Arrows indicate the site of the primary tumors. 


\section{Supplementary Figure Legends}

\section{Supplementary Figure 1: Demonstration of the intramuscular implantation}

technique and PDTX formation. (a) After the placement of a stay suture, a small IM pocket is created on the dorsum of the mouse, just large enough to accommodate the tumor piece. (b) Post implantation, the IM pocket is sutured closed with the implant evident immediately below the outer muscle fibers. (c) Gross view of an IM PDTX at time of harvest.

Supplementary Figure 2: Identification and characterization of lymphomagenic transformation within a subset of established PDTX. Immunohistochemistry using pan-cytokeratin AE1/AE3 (NCL-L-AE1/AE3, Novocastra/Leica Microsystems, Newcastle, UK, 1:100), CD20 (M7055, DakoCytomation, 1:200) and CD45 (M0701, DakoCytomation, 1:200) antibodies on original patient tumor and corresponding PDTX. The PDTX of patient 9 (a) is negative for the pan-cytokeratin marker, AE1/AE3, but positive for the common leukocyte antigen CD45 and the Blymphocyte restricted antigen CD20, indicating that it is predominately composed of human B-cells. In comparison, the PDTX of patient 16 (b) exhibits a combination of both epithelial cells (nests of AE1/AE3 positive cells) and lymphocytes. (c) Further analysis via flow cytometry (performed as previously described ${ }^{21}$ ) of single cells derived from PDTX 14 confirmed that the lymphoid cells were CD19+ B cells, as demonstrated in the left plot. The abnormal B cell population was then gated and is depicted on the FSC vs SSC plot in blue (right plot), indicating that these cells are also large. (d) In situ hybridization for Epstein Barr Virus (blue staining) was performed on sections of FFPE PDTX using the INFORM EBER Probe and ISH iVIEW Blue Detection Kit (Ventana/Roche, Tucson, AZ) as per the manufacturer's 
protocol and counterstained with eosin (pink). Left image is an EBV positive nasopharyngeal carcinoma (positive control); right image is a section from PDTX 9. 
Table 1: The matched pathological features and engraftment results from

implanted PDTX.

\begin{tabular}{|c|c|c|c|c|c|c|c|c|c|c|}
\hline \multirow[t]{2}{*}{ ID } & \multirow[t]{2}{*}{ Site $^{\mathrm{a}}$} & \multirow[t]{2}{*}{ Type } & \multirow[t]{2}{*}{ Grade } & \multirow{2}{*}{$\begin{array}{l}\text { Tissue } \\
\text { source }\end{array}$} & \multicolumn{2}{|c|}{$\frac{\text { Therapy prior to }}{\text { implantation }}$} & \multicolumn{2}{|c|}{$\underline{\text { Technique }^{\mathrm{b}, \mathrm{c}}}$} & \multirow{2}{*}{$\begin{array}{l}\text { Mouse } \\
\text { strain }\end{array}$} & \multirow{2}{*}{$\begin{array}{l}\text { Engraftment post } \\
\text { cryopreservation }\end{array}$} \\
\hline & & & & & CT & $\overline{\mathrm{RT}}$ & IM & SC & & \\
\hline 1 & GEJ & AC & Poor & Resection & $\mathrm{Y}$ & $\mathrm{N}$ & $1 / 4$ & $0 / 2$ & SCID & $2 / 2$ \\
\hline 2 & GEJ & $\mathrm{AC}$ & Poor & Resection & $\mathrm{Y}$ & $\mathrm{Y}$ & $1 / 2$ & & SCID & $2 / 2$ \\
\hline 3 & GEJ & $\mathrm{AC}$ & Mod & Resection & $\mathrm{Y}$ & $\mathrm{N}$ & & $0 / 4$ & NOD SCID & \\
\hline 4 & Esophageal & AC \& NE & Mod & Biopsy & $\mathrm{N}$ & $\mathrm{N}$ & $2 / 2$ & & NSG & \\
\hline 5 & Esophageal & $\mathrm{AC}$ & Mod to Poor & Biopsy & $\mathrm{N}$ & $\mathrm{N}$ & $1 / 2$ & & NOD SCID & $0 / 1$ \\
\hline 6 & Esophageal & $\mathrm{AC}$ & In-situ & Biopsy & $\mathrm{N}$ & $\mathrm{N}$ & $1 / 2$ & $0 / 1$ & NSG & \\
\hline 7 & Esophageal & SCC & Mod & Biopsy & $\mathrm{N}$ & $\mathrm{N}$ & $1 / 1$ & & NSG & \\
\hline 8 & Esophageal & AC & Mod & Biopsy & $\mathrm{N}$ & $\mathrm{N}$ & $1 / 1$ & & NSG & \\
\hline 9 & Esophageal & AC & Mod & Biopsy & $\mathrm{N}$ & $\mathrm{N}$ & $1 / 1^{\mathrm{d}}$ & $0 / 1$ & NSG & \\
\hline 10 & Esophageal & $\mathrm{AC}$ & Mod & Biopsy & $\mathrm{N}$ & $\mathrm{N}$ & $2 / 2$ & $1 / 2$ & NSG & $1 / 1$ \\
\hline 11 & Esophageal & SCC & Poor & Biopsy & $\mathrm{N}$ & $\mathrm{N}$ & $2 / 2$ & & NSG & $1 / 1$ \\
\hline 12 & Esophageal & SCC & Mod & Resection & $\mathrm{N}$ & $\mathrm{N}$ & $1 / 1$ & & NSG & \\
\hline 13 & PM from GEJ & $\mathrm{AC}$ & Mod to Poor & Resection & $\mathrm{N}$ & $\mathrm{N}$ & $1 / 2$ & & NSG & \\
\hline 14 & Esophageal & $\mathrm{AC}$ & Poor & Resection & $\mathrm{Y}$ & $\mathrm{N}$ & $1 / 3$ & & NSG & \\
\hline 15 & GEJ & $\mathrm{AC}$ & Mod & Biopsy & $\mathrm{N}$ & $\mathrm{N}$ & $2 / 3$ & & NSG & \\
\hline 16 & Esophageal & AC & Poor & Resection & $\mathrm{N}$ & $\mathrm{N}$ & $1 / 2^{\mathrm{e}}$ & & NSG & \\
\hline 17 & Esophageal & SCC & In-situ & Biopsy & $\mathrm{N}$ & $\mathrm{N}$ & $1 / 1$ & $0 / 1$ & NSG & \\
\hline 18 & Esophageal & $\mathrm{AC}$ & Mod & Biopsy & $\mathrm{N}$ & $\mathrm{N}$ & $1 / 2$ & & NSG & \\
\hline 19 & Esophageal & AC \& NE & Poor & Biopsy & $\mathrm{Y}$ & $\mathrm{N}$ & $3 / 4$ & & NSG & \\
\hline
\end{tabular}

a Abbreviations: GEJ, gastro-esophageal junction; PM, peritoneal metastasis; AC, adenocarcinoma; NE, neuroendocrine differentiation; SCC, squamous cell carcinoma; CT, chemotherapy; RT, radiotherapy; IM, intramuscular; SC, subcutaneous.

${ }^{\mathrm{b}}$ Fractions indicate the number of successful engraftments over the total number of implants.

${ }^{\mathrm{c}}$ Shaded, lymphomatous transformation within engrafted tumor; blank, not attempted.

${ }^{\mathrm{d}}$ Transformation occurred at second passage.

e Mixed epithelial component. 
Figure 1
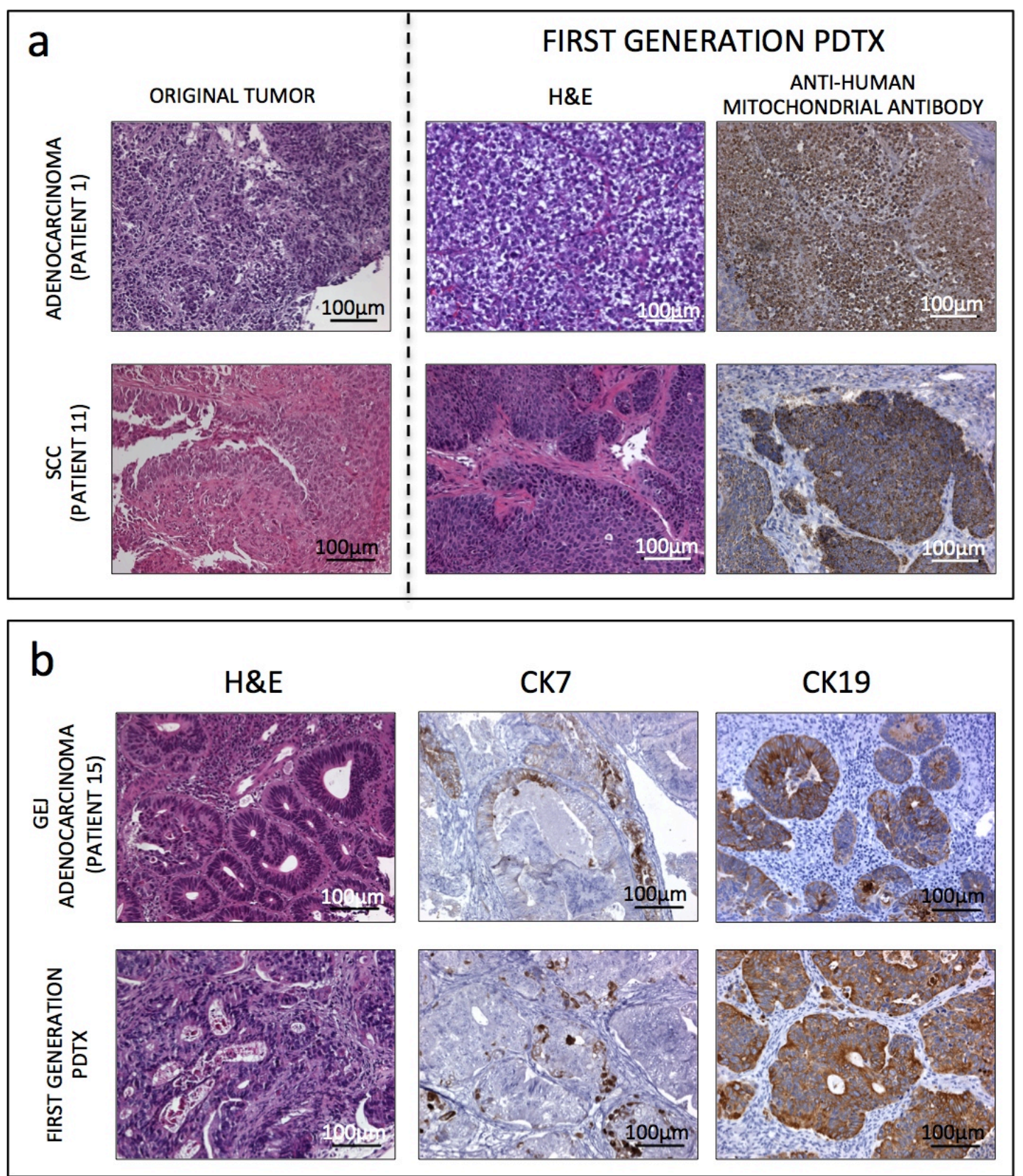
Figure 2
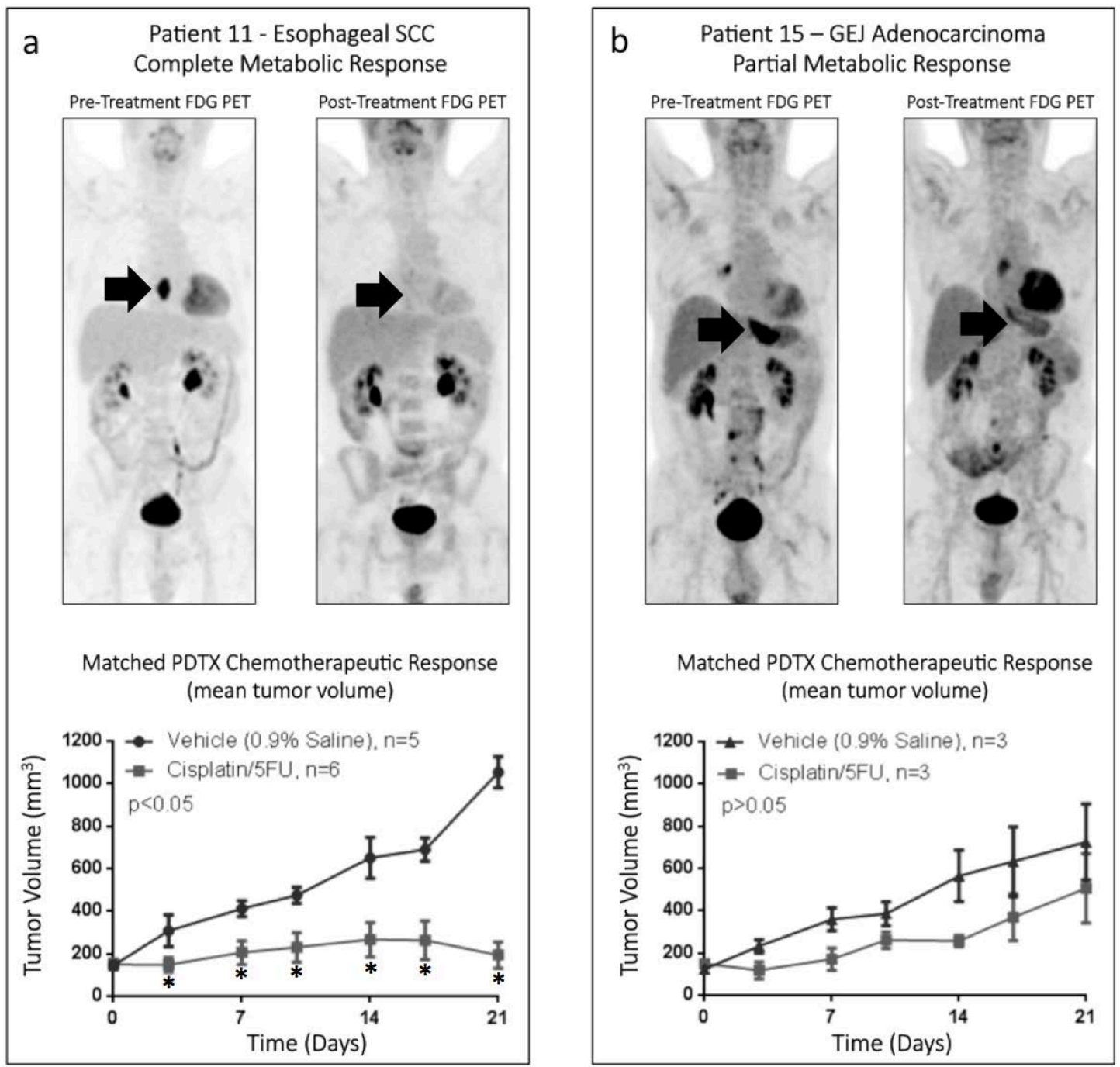
Supplementary Figure 1
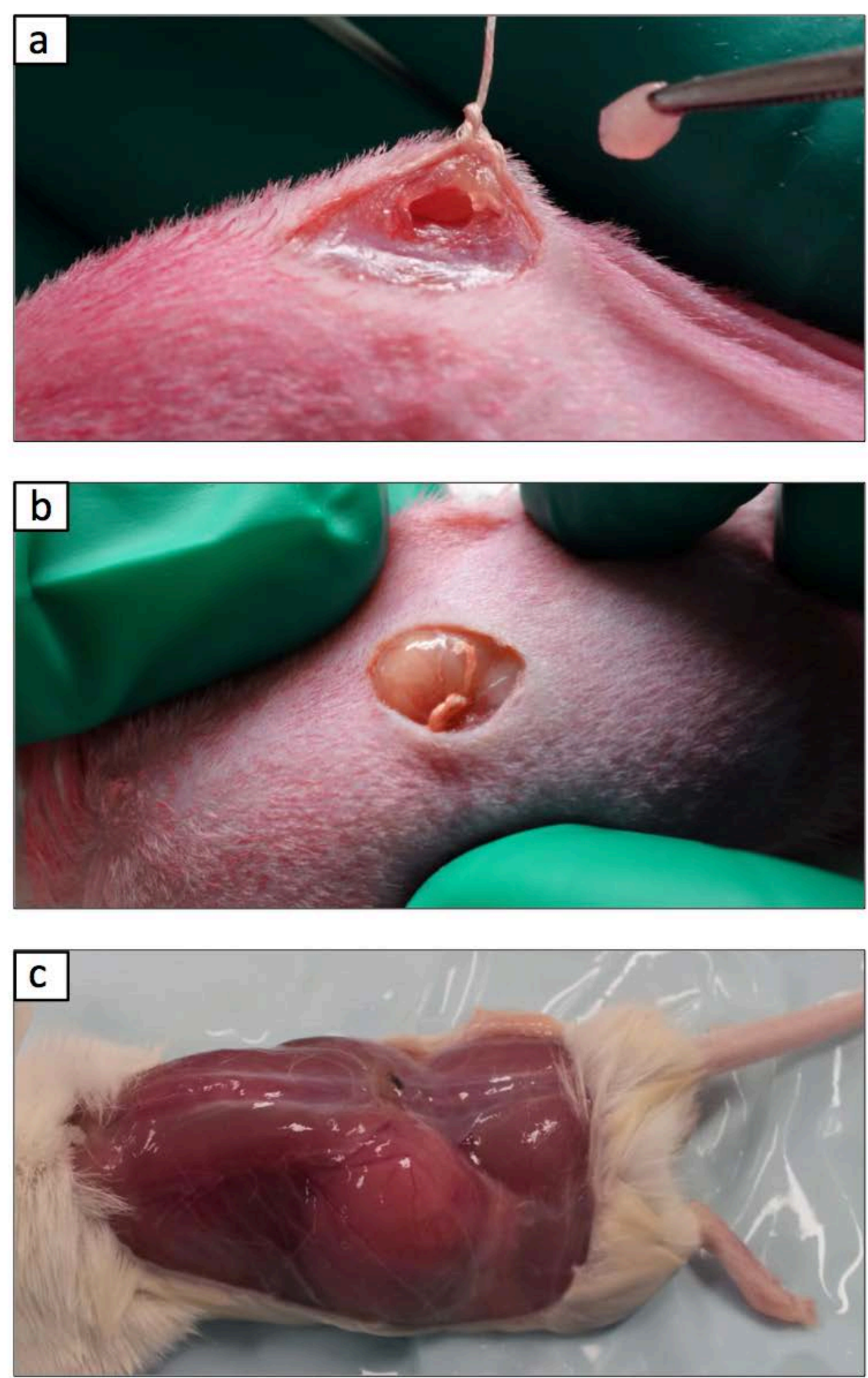


\section{Supplementary Figure 2}

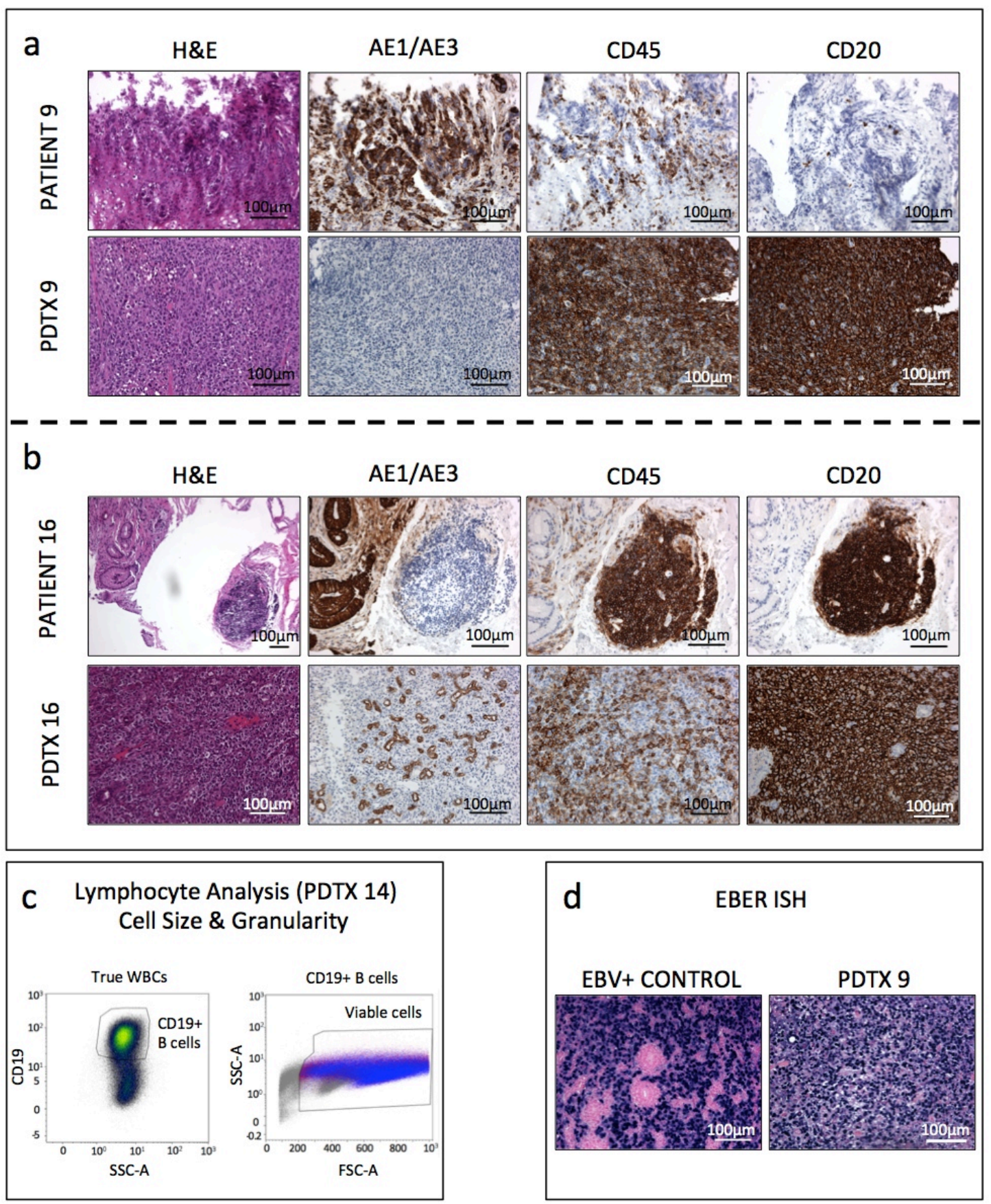




\section{University Library}

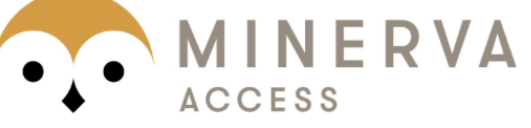

A gateway to Melbourne's research publications

Minerva Access is the Institutional Repository of The University of Melbourne

Author/s:

Read, M;Liu, D;Duong, CP;Cullinane, C;Murray, WK;Fennell, CM;Shortt, J;Westerman, D;Burton, P;Clemons, NJ;Phillips, WA

Title:

Intramuscular Transplantation Improves Engraftment Rates for Esophageal Patient-Derived Tumor Xenografts

Date:

2016-01-01

Citation:

Read, M., Liu, D., Duong, C. P., Cullinane, C., Murray, W. K., Fennell, C. M., Shortt, J., Westerman, D., Burton, P., Clemons, N. J. \& Phillips, W. A. (2016). Intramuscular Transplantation Improves Engraftment Rates for Esophageal Patient-Derived Tumor Xenografts. ANNALS OF SURGICAL ONCOLOGY, 23 (1), pp.305-311. https:// doi.org/10.1245/s10434-015-4425-3.

Persistent Link:

http://hdl.handle.net/11343/123673 